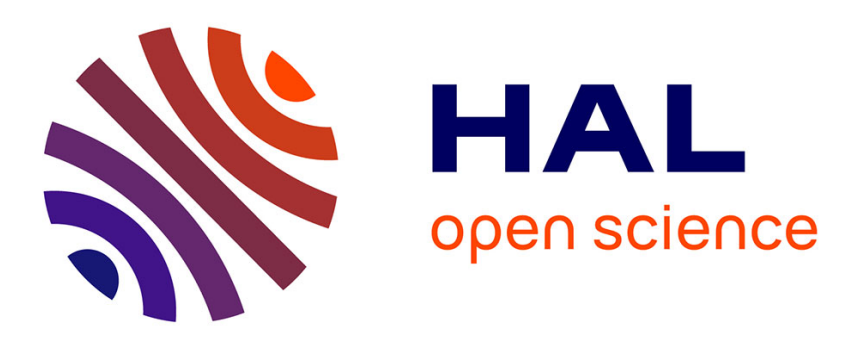

\title{
Investigation on statistical tools to analyze repetitive-electrostatic-discharge endurance of system-level protections
}

Marianne Diatta, David Trémouilles, Emilien Bouyssou, Marise Bafleur

\section{- To cite this version:}

Marianne Diatta, David Trémouilles, Emilien Bouyssou, Marise Bafleur. Investigation on statistical tools to analyze repetitive-electrostatic-discharge endurance of system-level protections. IEEE Transactions on Device and Materials Reliability, 2012, 12 (4), pp.607-614. 10.1109/TDMR.2012.2230093 . hal-00787197

\section{HAL Id: hal-00787197 \\ https://hal.science/hal-00787197}

Submitted on 11 Feb 2013

HAL is a multi-disciplinary open access archive for the deposit and dissemination of scientific research documents, whether they are published or not. The documents may come from teaching and research institutions in France or abroad, or from public or private research centers.
L'archive ouverte pluridisciplinaire HAL, est destinée au dépôt et à la diffusion de documents scientifiques de niveau recherche, publiés ou non, émanant des établissements d'enseignement et de recherche français ou étrangers, des laboratoires publics ou privés. 


\title{
Investigation on Statistical Tools to Analyze Repetitive- Electrostatic-Discharge Endurance of System-Level Protections
}

\author{
Marianne Diatta, David Trémouilles, Emilien Bouyssou, Marise Bafleur
}

\begin{abstract}
To fulfill the requirement of final-users uncontrolled ESD-environment, system level ESD protection devices must survive repeated ESD stresses. This paper deals with the assessment of ESD protection devices reliability towards repetitive stresses using statistical distribution. The proposed method could lead to better ESD robustness improvement than the simplistic "higher ESD robustness" requirement.
\end{abstract}

Index Terms - Electrostatic discharge, ESD, Reliability, Endurance, System-level.

\section{INTRODUCTION}

$\mathrm{E}$ LECTRONIC devices become more and more portable and widespread as technologies scale down. Hence, efficient ElectroStatic Discharge (ESD) protection devices are required to ensure good system robustness as, for example, in automotive or hand held applications. The challenge of adopting new and more stringent reliability test conditions, like repetitive ESD stresses, is important to offer better robustness towards what the device will actually see in the hands of customers in the field.

Qualifying devices for repetitive stress robustness could be more important than reaching very high single shot stress robustness. Indeed, a $20 \mathrm{kV}$ ESD robust system can still prove to be unreliable if it has a slight probability of failure at $15 \mathrm{kV}$ during repetitive stress, since the prevalence of low voltage electrostatic discharge in typical system environment might be easily admitted [1]. This evidence that repetitive stress is an important ESD reliability issue.

Manuscript received October 9, 2001. (Write the date on which you submitted your paper for review.) This work was supported in part by the U.S. Department of Commerce under Grant BS123456 (sponsor and financial support acknowledgment goes here). Paper titles should be written in uppercase and lowercase letters, not all uppercase. Avoid writing long formulas with subscripts in the title; short formulas that identify the elements are fine (e.g., "Nd-Fe-B"). Do not write "(Invited)" in the title. Full names of authors are preferred in the author field, but are not required. Put a space between authors' initials.

F. A. Author is with the National Institute of Standards and Technology, Boulder, CO 80305 USA (corresponding author to provide phone: 303-5555555; fax: 303-555-5555; e-mail: author@ boulder.nist.gov).

S. B. Author, Jr., was with Rice University, Houston, TX 77005 USA. He is now with the Department of Physics, Colorado State University, Fort Collins, CO 80523 USA (e-mail: author@lamar.colostate.edu).

T. C. Author is with the Electrical Engineering Department, University of Colorado, Boulder, CO 80309 USA, on leave from the National Research Institute for Metals, Tsukuba, Japan (e-mail: author@nrim.go.jp).
To fulfill the lack of clear repetitive stress definition and understanding, we introduce in this work the concept of ESD "endurance" that is defined as the capability of a device to survive repetitive ESD stress. Thus the ESD endurance of a device is different and complements the classical "ESD robustness" definition, which usually corresponds to the maximum safe ESD-stress level a device can survive.

In this paper, we investigate on the most efficient methodology to analyze ESD immunity in a repetitive stress mode. The aim of this work is to build a solid framework for repetitive ESD reliability analysis.

The first section describes the studied device and the way experiments are carried-out. The raw measurement results of ESD endurance and ESD robustness are discussed in the second section. In the third section different statistical approaches are investigated and compared to define the best way to characterize ESD endurance.

\section{MEASUREMENT TECHNIQUES}

\section{A. ESD Protection Device}

The studied devices are back-to-back protection diodes (Figure 1). Both diodes have been processed on the same substrate whereas $\mathrm{In} / \mathrm{Out}(\mathrm{I} / \mathrm{O})$ and ground junction have the same doping profile. This bidirectional structure offers a protection for both positive and negative ESD current stresses. 


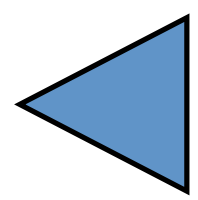

Figure 1: Electrical scheme of the bidirectional ESD protection diode.

Indeed, for both positive and negative ESD current stresses, one diode is forward biased while the other one is reverse biased. Neither snapback nor any bipolar effect is observed due to the large distance separating the diodes $(>30 \mu \mathrm{m})$. However, conductivity modulation by the forward biased diode allows reducing the serial resistance of the whole device.

The diode contact on which the stress is applied is named In/Out while the other one is named ground. In this paper, investigations are performed on three process splits (A, B and C) having different process conditions suspected to impact repetitive ESD reliability.

\section{B. HMM Tests}

As a preamble, it might be important to underline that in this work we are considering ESD as a destructive event and not an immunity problem, as more generally defined in ElectroMagnetic Compatibility (EMC) area.

It is also important to underline that it does not make sense to apply the method proposed here with HBM, MM or CDM type of stress standards. Indeed these three models are defined to provide ESD robustness for IC assembly in ESD Protected Area (EPA) where ESD is actually very unlikely to happen nowadays. One could actually expect that an IC would almost never see any ESD stress and in the worst case only very few of them in an EPA. In opposite, HMM type of stress, at the system level, models ESD events in usually totally uncontrolled ESD environment where ESD will occur at any possible levels (for example mobile phones must survive many ESD stress over their lifetime).

\section{1) Test Setup}

The International Electrotechnical Commission (IEC) publishes the 61000-4-2 standard to test the immunity of electronic systems to ESD. However, although this standard application is not adapted to integrated circuits, this is an increasing request from system designers. To broaden the application of this IEC standard to integrated circuits and to ensure a reliable measurement method, a standard practice was proposed by the ElectroStatic Discharge Association (ESDA): the Human Metal Model (HMM). HMM reproduces the IEC61000-4-2-standard waveform simulating the discharge of a person through a metallic tool [2].

To overcome the issue of often non reproducible results with typical ESD guns, an alternative test method based on a $50 \Omega$ transmission line tester has been proposed to produce IEC type pulses.

For this work, the Barth 4702IEC-50 test system has been used to deliver HMM pulses up to $30 \mathrm{kV}$, in accordance with the IEC 61000-4-2 standard and the ESDA HMM recommendations. All tests are performed on wafer. It has to be noticed that there is a good correlation of the ESD robustness between packaged devices tested with an IEC gun and with Barth 4702IEC-50 testers. We also observed excellent agreement between devices tested at wafer level and packaged ones using the Barth tester [3]. Nevertheless, it is 
worth underlining that any general and universal correlation law could be defined from these results.

\section{2) Single ESD Robustness}

For a single ESD zap, it turns out that very similar ESD robustness performances are obtained for the three process splits. This could be expected as the layout of all devices is strictly identical.

For each process split, 40 samples were characterized. The plot of single ESD robustness $V_{E S D O}$ measurements as a function of the process split shows that the averages of single HMM stress robustness is $16.3 \mathrm{kV}$ for all splits (Figure 2).

The statistical scattering of robustness seems to be slightly improved with process $\mathrm{C}$.

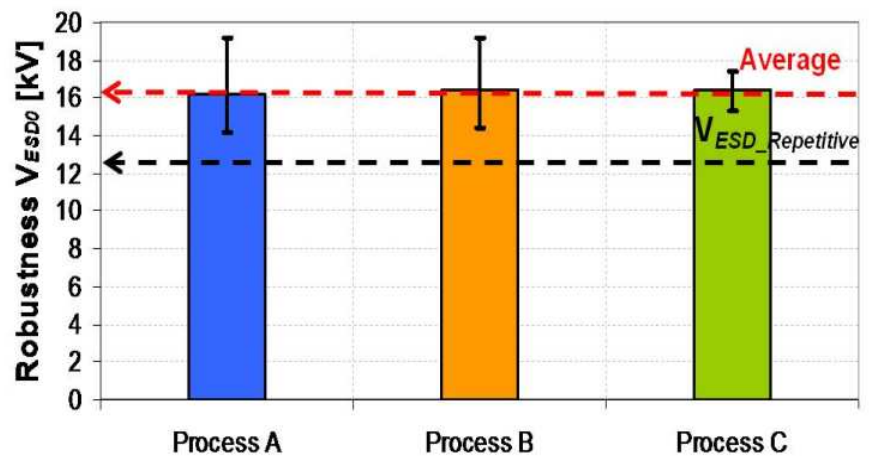

Figure 2: Single HMM stress robustness $V_{E S D O}$ as a function of

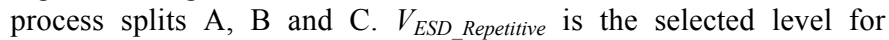
repetitive ESD stress. The errors bars correspond to the minimum and the maximum $V_{E S D O}$ measurements obtained.

For the repetitive ESD measurement, the applied ESD

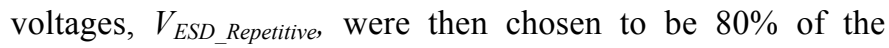
average ESD robustness $V_{E S D O}$, that is to say $V_{\text {ESD_Repetitive }}=13 \mathrm{kV}$ (Figure 2). In this condition, device degradation is ensured to not being related to single ESD failure mode as no device failed at this level during single stress tests. Indeed, on the one hand, our tests show that many devices failed after less than 200 pulses when stressed at $90 \%$ of $V_{E S D O}$, which revealed that many of these devices might have failed by the same physical mechanisms as the one occurring for single stress. On the other hand for ESD stress repeated at $70 \%$ of $V_{E S D}$, degradations are only observed for a rather high number of pulses and, as a consequence, quite a long test time is required, which is not practical to carry out an extensive statistical analysis. To summarize, the repetitive mode of degradation cannot be distinguished from single robustness degradation at $90 \%$ of $V_{E S D}$ and statistical analysis would be cumbersome at $70 \%$ of $V_{E S D O}$. To focus the study on the repetitive-stress mechanisms, the devices degraded at $80 \%$ have only been considered in this paper.

\section{EXPERIMENT RESULTS}

\section{A. Measurements}

No standard exists yet to evaluate repetitive ESD robustness. However, it has been proven that protection devices could show weaknesses when stressed with repetitive surges [4] [5] [6].

During ESD tests, the devices are connected as shown in Figure 1. Positive zaps are applied to the I/O junction while Ground junction is connected to ground. Negative zaps are not considered here. Indeed, the lowest robustness configuration corresponds to the configuration where the $\mathrm{I} / \mathrm{O}$ junction is reverse biased during ESD stress. The ground junction is more robust than the $\mathrm{I} / \mathrm{O}$ junction thanks to its total area that is much larger

In this work, repetitive-stress robustness testing is carried-out applying ESD pulses at a repetition frequency of $10 \mathrm{~Hz}$ for a given stress voltage ( $V_{E S S_{-} \text {Repetitive }}$ ), that is lower than the single ESD robustness level.

The number of ESD pulses, $N_{B D}$, leading to electrical degradation is determined in the following way. The device functions are automatically checked after a set of 50 ESD stresses. If the electrical Current-Voltage (I-V) characteristics are identical to the one recorded before any stress, the test procedure continues until the device fails. The failure is defined as a major change in measured electrical performance. Here we consider the criterion as a ten-time increase of the leakage current measured at a voltage equal to $90 \%$ of the diode breakdown voltage.

Raw data measurements for each process split are given in tables 1, 2 and 3. The first column represents the number of devices failing at the same level i.e. after the same total number of ESD pulses. After the end of the test, the device state can either be "failed" or a "suspended". Failed devices present a degraded I-V characteristic and are considered not functional anymore. Suspended devices do not show any electrical degradation or failure. In table one we see that seven devices did not failed after 3000 pulses. Indeed, for each device test, it is necessary to limit the applied total number of pulse to a maximum in order to master the test time. If not, the samples having high repetitive stress capability will take too long to test. Thus, for this device the test is stopped at a given number of pulse and the device is labeled as "suspended".

Even if the number of pulse that suspended devices do sustain is not known, there is still piece of information in the fact that they sustain at least a given number of pulses. This can practically be taken into account through the statistical method exploited in this work.

Table 1: Experimental results of ESD repetitive characterization mode for Process A split. $\mathrm{V}_{E S D \_ \text {Repetitive }}=80 \% \mathrm{~V}_{E S D O}$.

\begin{tabular}{|c|c|c|c|}
\hline $\begin{array}{c}\text { Number of } \\
\text { devices } \\
\text { in State }\end{array}$ & $\begin{array}{c}\text { Number of } \\
\text { ESD pulses } \\
\text { at the last } \\
\text { inspection }\end{array}$ & $\begin{array}{c}\text { Device State: } \\
\text { Failed (F) } \\
\text { or Suspended (S) }\end{array}$ & $\begin{array}{c}\text { Number of ESD } \\
\text { pulses } \\
\text { at the failure } \\
\mathrm{N}_{B D}\end{array}$ \\
\hline 4 & 0 & $\mathrm{~F}$ & 50 \\
3 & 50 & $\mathrm{~F}$ & 100 \\
4 & 100 & $\mathrm{~F}$ & 150 \\
1 & 250 & $\mathrm{~F}$ & 300 \\
3 & 300 & $\mathrm{~F}$ & 350 \\
4 & 400 & $\mathrm{~F}$ & 450 \\
4 & 450 & $\mathrm{~F}$ & 500 \\
5 & 500 & $\mathrm{~F}$ & 550
\end{tabular}




\begin{tabular}{|c|c|c|c|}
1 & 550 & $F$ & 600 \\
1 & 600 & $F$ & 650 \\
1 & 700 & $F$ & 750 \\
1 & 750 & $F$ & 800 \\
1 & 950 & $F$ & 1000 \\
$\mathbf{7}$ & $\mathbf{2 9 5 0}$ & S & $>\mathbf{3 0 0 0}$ \\
\hline
\end{tabular}

Table 2 : Experimental results of ESD repetitive characterization mode for Process B split. $\mathrm{V}_{E S D \_ \text {Repetitive }}=80 \% \mathrm{~V}_{E S D O}$.

\begin{tabular}{|c|c|c|c|}
\hline $\begin{array}{c}\text { Number of } \\
\text { devices in } \\
\text { State }\end{array}$ & $\begin{array}{c}\text { Number of } \\
\text { ESD pulses } \\
\text { at the last } \\
\text { inspection }\end{array}$ & $\begin{array}{c}\text { Device State: } \\
\text { Failed (F) } \\
\text { or Suspended (S) }\end{array}$ & $\begin{array}{c}\text { Number of } \\
\text { ESD pulses } \\
\text { at the failure } \\
\mathrm{N}_{B D}\end{array}$ \\
\hline 2 & 50 & $\mathrm{~F}$ & 150 \\
1 & 150 & $\mathrm{~F}$ & 200 \\
4 & 250 & $\mathrm{~F}$ & 300 \\
1 & 300 & $\mathrm{~F}$ & 350 \\
2 & 350 & $\mathrm{~F}$ & 400 \\
3 & 400 & $\mathrm{~F}$ & 450 \\
2 & 450 & $\mathrm{~F}$ & 500 \\
9 & 500 & $\mathrm{~F}$ & 550 \\
6 & 550 & $\mathrm{~F}$ & 600 \\
2 & 600 & $\mathrm{~F}$ & 650 \\
1 & 650 & $\mathrm{~F}$ & 700 \\
1 & 750 & $\mathrm{~F}$ & 800 \\
1 & 2950 & $\mathrm{~F}$ & 3000 \\
$\mathbf{5}$ & $\mathbf{2 9 5 0}$ & $\mathrm{S}$ & $>\mathbf{3 0 0 0}$ \\
\hline
\end{tabular}

Table 3: Experimental results of ESD repetitive characterization mode for Process C split. $\mathrm{V}_{E S D \text { Repetitive }}=80 \% \mathrm{~V}_{E S D O}$.

\begin{tabular}{|c|c|c|c|}
\hline $\begin{array}{c}\text { Number of } \\
\text { devices in State }\end{array}$ & $\begin{array}{c}\text { Number of } \\
\text { ESD pulses } \\
\text { at the last } \\
\text { inspection }\end{array}$ & $\begin{array}{c}\text { Device State: } \\
\text { Failed (F) } \\
\text { or Suspended (S) }\end{array}$ & $\begin{array}{c}\text { Number of } \\
\text { ESD pulses } \\
\text { at the failure } \\
\mathrm{N}_{B D}\end{array}$ \\
\hline 1 & 500 & $\mathrm{~F}$ & 550 \\
1 & 1550 & $\mathrm{~F}$ & 1600 \\
1 & 3250 & $\mathrm{~F}$ & 3300 \\
1 & 4150 & $\mathrm{~F}$ & 4200 \\
1 & 4650 & $\mathrm{~F}$ & 4700 \\
1 & 5450 & $\mathrm{~F}$ & 5500 \\
1 & 5850 & $\mathrm{~F}$ & 5900 \\
1 & 6550 & $\mathrm{~F}$ & 6600 \\
1 & 6950 & $\mathrm{~F}$ & 7000 \\
1 & 7250 & $\mathrm{~F}$ & 7300 \\
3 & 7550 & $\mathrm{~F}$ & 7600 \\
1 & 7650 & $\mathrm{~F}$ & 7700 \\
1 & 7850 & $\mathrm{~F}$ & 7900 \\
1 & 7950 & $\mathrm{~F}$ & 8000 \\
1 & 8650 & $\mathrm{~F}$ & 8700 \\
1 & 10250 & $\mathrm{~F}$ & 10300 \\
1 & 10750 & $\mathrm{~F}$ & 10800 \\
1 & 14450 & $\mathrm{~F}$ & 14500 \\
1 & 14650 & $\mathrm{~F}$ & 14700 \\
1 & 17950 & $\mathrm{~F}$ & 18000 \\
1 & 20050 & $\mathrm{~F}$ & 20100 \\
1 & 23550 & $\mathrm{~F}$ & 23600 \\
1 & 24450 & $\mathrm{~F}$ & 25000 \\
1 & 25750 & $\mathrm{~F}$ & 25800 \\
\hline
\end{tabular}

\section{B. Reliability in Repetitive Mode}

At first thought, one would expect to obtain similar robustness in repetitive HMM stress mode for the three process splits, since the single stress results are equivalent to, and independent of, the process type. Unexpectedly, process C devices appear to sustain a very significantly higher number of stress repetitions $\left(N_{B D}\right)$ (Figure 3).

The maximum number of stresses repeated on a sample has been limited to 30,000 pulses for Process $\mathrm{C}$ and 3,000 pulses for Process A and B.

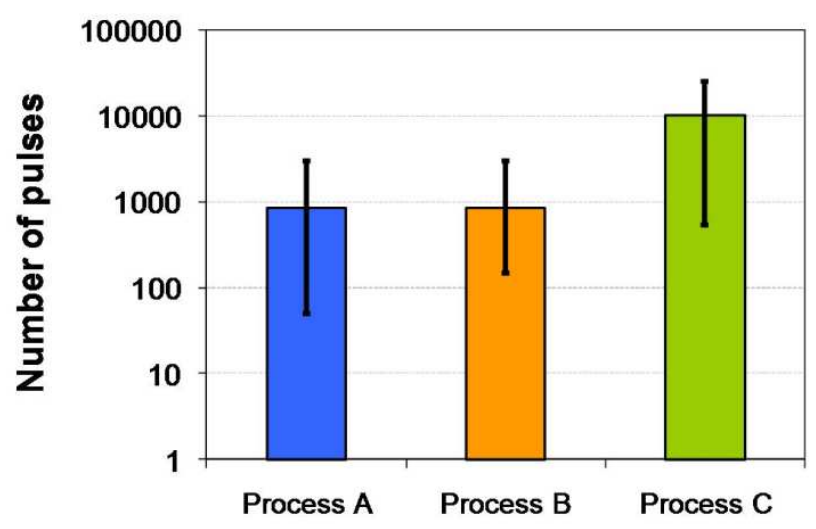

Figure 3: Number of pulses $\boldsymbol{N}_{\boldsymbol{B} \boldsymbol{D}}$ leading to electrical failure during HMM pulses repetition (log scale). Average, maximum and minimum are reported as a function of the device type based on 40 samples for each process.

The data leads to an objective conclusion that qualitatively, the process $\mathrm{C}$ split offers better ESD reliability or ESD endurance than the A or B splits. Nevertheless, the overlap of the error bars does not guarantee a significantly longer device lifetime for process $\mathrm{C}$ than for process $\mathrm{A}$ or $\mathrm{B}$. Therefore, the simple representation of the average, the minimum and the maximum number of pulses encounters limitations for ensuring ESD reliability of protection devices. To guarantee reliable products regarding repetitive electrostatic discharges, a more suitable statistical methodology is required to guide the development of protection devices with better ESD endurance [7].

\section{STATISTICAL MODELING}

Applying mathematical formalism, the probability to obtain a value $x$ on series of measurement for an event $X$ is described by the Probability Density Function $(p d f)$ named $f(x)$. In this paper, the event $X$ corresponds to the failure of the bidirectional diode during repetitive stress. The number of ESD pulses leading to degradation $N_{B D}$ is the random variable $x$. As a result, the probability to obtain the result $N_{B D}$ is given by the $p d f, f\left(N_{B D}\right)$.

The cumulative distribution function $(c d f)$ named $F\left(N_{B D}\right)$ represents the probability of getting an electrical failure for $x \leq \mathrm{N}_{\mathrm{BD}}$ value. Consequently, the relation between $f$ and $F$ is given through: 


$$
F\left(N_{B D}\right)=\int_{0}^{N_{B D}} f(x) d x
$$

The $c d f$ representation is a practical way to encompass both continuous and discrete distributions. The discrete distribution is estimated from the measurement results based on the ranking method while the continuous distribution consists in a fit to the applied statistical distributions. When discrete and continuous distributions are in very close agreement, one can conclude that the studied statistical distribution models the experimental distribution correctly.

In the following sections, different statistical distributions are studied to define the most accurate distribution that models the reliability towards repetitive HMM stresses.

Exponential, normal, lognormal and Weibull distributions are widely used functions to investigate on reliability.

Since the exponential distribution is a particular case of the Weibull distribution $(\beta=1)$, the research has been limited to the normal, lognormal and Weibull distributions.

The specificity of the experimental function requires adapted statistical treatment. Raw data summarized in tables 1, 2 and 3 should remind that the maximum number of pulses has been defined at 3,000 pulses for process A and B, and 30,000 pulses for process $\mathrm{C}$. This means that most devices exhibited signs of electrical degradation by the end of the test. The devices that have sustained 3,000 (process A and B) or 30,000 (process C) pulses without any leakage evolution are named "right censored" data. In addition, as electrical tests are done only every 50 pulses, the exact number of pulses leading to the electrical degradation for a given device is unknown but, in the range of 50. In this case, we have so called intervalcensored data. Both censoring aspects need to be taken into account in the statistical approach. We will not give the details of how to manage such data in this paper but let the reader consult reliability and statistic books [14].

The study is carried out using the Weibull ++7 software edited by ReliaSoft [8], which was selected for its flexibility and availability.

The selected Maximum Likelihood Estimation (MLE) based method allows proper treatment of right and interval censored data.

In this study, the statistical analysis has been performed on 40 protection devices for each process type. Identical sampling and experimental conditions allows performing a consistent statistical comparison.

\section{A. Normal Distribution}

The normal distribution, also known as the Gaussian distribution, is the most widely-used for general purpose distribution to establish statistical performances of products and processes. For that reason, the normal distribution is included among the lifetime distributions commonly used for reliability and lifetime data analysis [9]. The distribution is a bell-shaped function with a maximum at $\mathrm{X}=\mu$ denoting the central tendency of results. The spreading of the distribution is characterized by the variance designated by the term $\sigma$ in the expression below of the probability density function:

$$
f(x)=\frac{1}{\sqrt{2 \pi \sigma^{2}}} \exp \left[-\left(\frac{(x-\mu)^{2}}{2 \sigma^{2}}\right)\right]
$$

The standard deviation, $\sigma$, is the scale parameter of the normal $p d f$. Note that the spread is broader on both sides of $\mu$ when $\sigma$ is larger. The $\sigma$ and $\mu$ parameters calculated for the three process splits are summarized in Table 4.

Table 4: Experimental parameters $\mu$ and $\sigma$ established from normal distribution for process A, B and C splits.

\begin{tabular}{|c|c|c|c|}
\cline { 2 - 4 } \multicolumn{1}{c|}{} & Process A & Process B & Process C \\
\hline $\boldsymbol{N}_{\boldsymbol{B} \boldsymbol{D}}=\mu$ & $\mathbf{9 1 2}$ & $\mathbf{8 8 7}$ & $\mathbf{1 0 1 3 1}$ \\
\hline Sigma $(\sigma)$ & 1228 & 1039 & 6875 \\
\hline$\mu / \sigma$ & 0.74 & 0.85 & 1.47 \\
\hline
\end{tabular}

From Figure 4, it can be seen that globally process $\mathrm{C}$ provides the best ESD reliability in a repetitive stress mode. Indeed, the abscissa of the maximum of the bell ( $\mu$ parameter) is dramatically superior, despite a smaller $\sigma$ for process A and B. This statistical analysis shows that process A and B exhibit less dispersion compared to process $\mathrm{C}$ regarding repetitive ESD robustness.

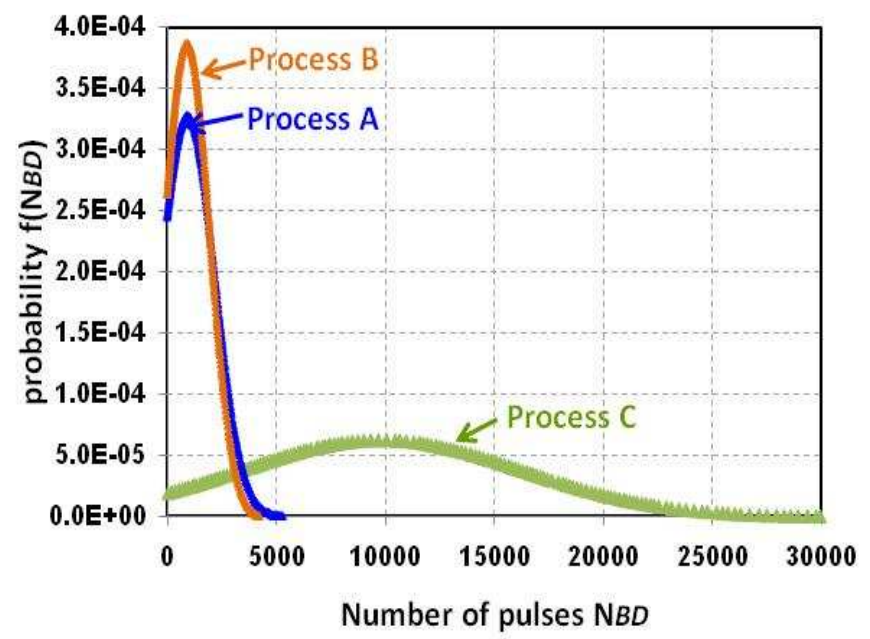

Figure 4: Normal Probability Density Function for process A, B and C. All plots have been obtained with Weibull ++7 software.

As it could be expected, no useful additional information is provided by the normal distribution compared to the simple average/minimum/maximum representation shown in section III.

One could also argue that the normal distribution is inappropriate for modeling lifetime data because the left-hand limit of the distribution extends to negative infinity (Figure 4), which is practically nonsense. Note that average and standard deviation should match $\mu$ and $\sigma$ if Gaussian is the distribution form. 


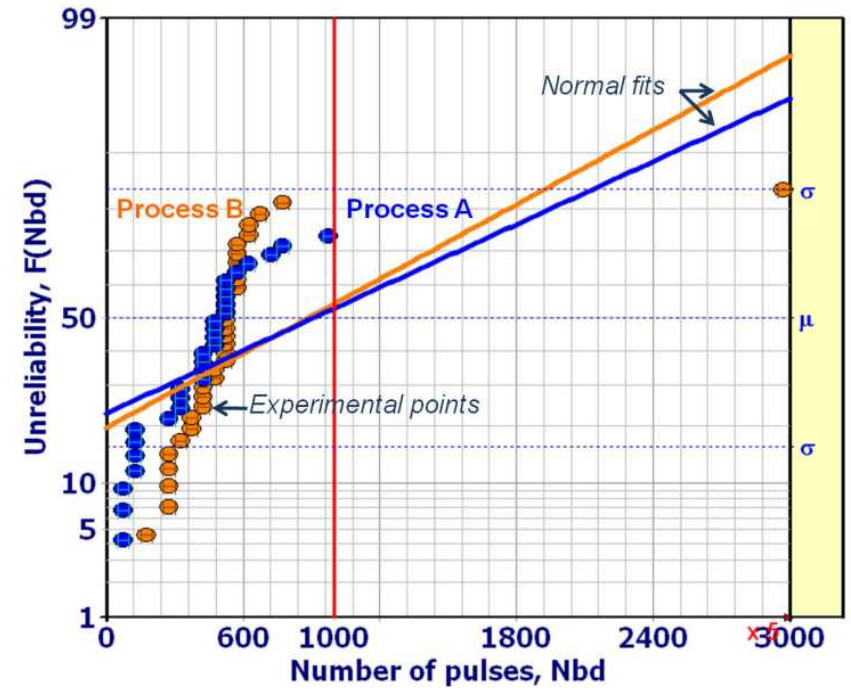

Figure 5: Cumulative probability density function $F\left(N_{B D}\right)$ plot following the normal distribution for process $\mathrm{A}$ and $\mathrm{B}$ splits.

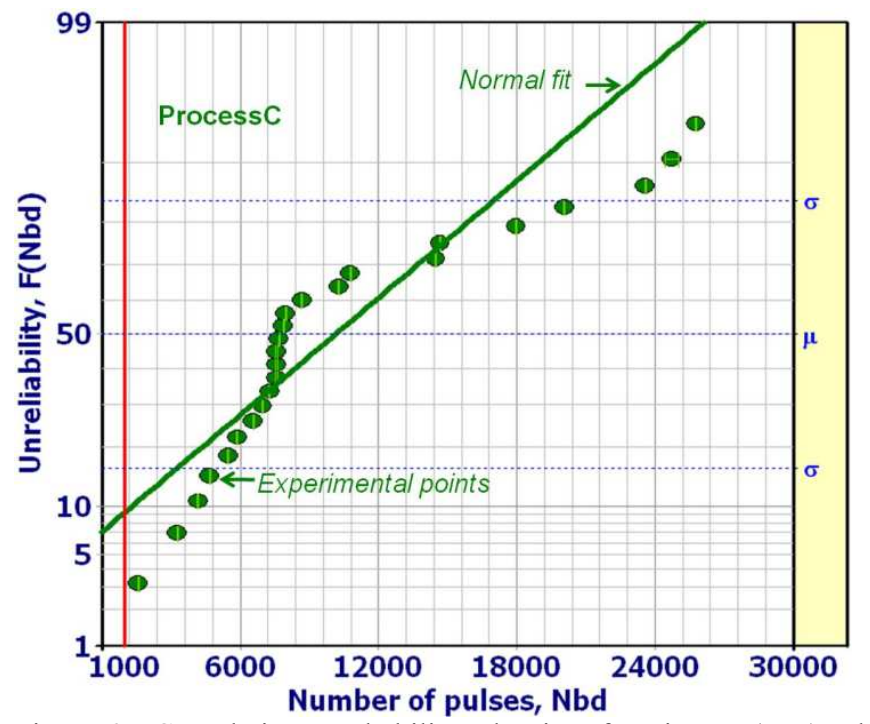

Figure 6: Cumulative probability density function $F\left(N_{B D}\right)$ plot following the normal distribution for process process $\mathrm{C}$ split.

In addition, the normal distribution fit does not match with the $c d f$ estimated from the experimental points (Figure 5 and Figure 6). The widespread of the number of ESD pulses on several decades have been assumed to be the root cause of the mismatch between experimental points and fitted data. Indeed, the number of devices suspended at 3,000 pulses is considerable. Therefore, the lognormal distribution is seen to be more suited than the normal distribution to many situations where large dispersion of the observed quantities is found [9]. Consequently, linear scale and the extension to negative data show that the normal probability distribution is inadequate to study the statistical distributions of repetitive ESD endurance. A study on a lognormal distribution has been carried out to get more meaningful results because lognormal solves the problem of the extension to negative values.

\section{B. Lognormal Distribution}

The lognormal probability density function is given by the following equation:

$$
f(x)=\frac{1}{x \sigma \sqrt{2 \pi}} \exp \left[-\frac{(\ln x-\mu)^{2}}{2 \sigma^{2}}\right] .
$$

From the $c d f$ plots, one can argue that lognormal fits are better than normal distribution plots despite a certain mismatch between the lognormal fit and the $c d f$ points estimated from measurement (Figure 7). We can observe the good behavior of the distribution around zero.

Indeed, in Figure 7 the points represent cumulative probability calculated from experimental results while the lines correspond to the fit of the lognormal distribution.

From Weibull ++7 , we extract the parameters $\mu$ and $\sigma$ where $\mu$ is the mean of the natural logarithm of the number of ESD leading to failure and $\sigma$ describes the standard deviation of $\mu$. In the table below, $\mu$ and $\sigma$ are given for each process split.

Table 5: Experimental parameters $\mu$ and $\sigma$ established from lognormal distribution for process $\mathrm{A}, \mathrm{B}$ and $\mathrm{C}$ splits.

\begin{tabular}{|c|c|c|c|}
\cline { 2 - 4 } \multicolumn{1}{c|}{} & Process A & Process B & Process C \\
\hline $\boldsymbol{N}_{\boldsymbol{B} \boldsymbol{D}}$ & $\mathbf{3 8 8}$ & $\mathbf{5 2 0}$ & $\mathbf{7 6 9 2}$ \\
\hline $\boldsymbol{I n}\left(\boldsymbol{N}_{\boldsymbol{B D}}\right)=\mu$ & $\mathbf{5 . 9 6 1}$ & $\mathbf{6 . 2 5 4 6}$ & $\mathbf{8 . 9 4 8}$ \\
\hline Sigma $(\sigma)$ & 0.95 & 0.44 & 0.86 \\
\hline$\mu / \sigma$ & 6.27 & 14.21 & 10.04 \\
\hline
\end{tabular}

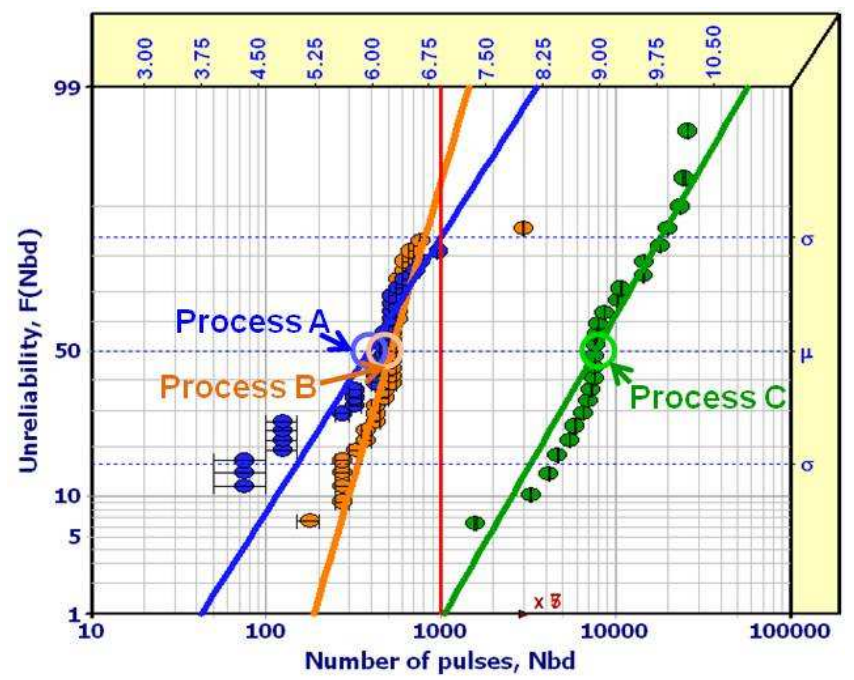

Figure 7: Cumulative probability density function $F\left(N_{B D}\right)$ plot following lognormal distribution

\section{Weibull Distribution}

The Weibull distribution is the most popular statistical model for lifetime data [11] [12]. In fact, Billiton and Adam confirmed that the Weibull distribution can also be used for modeling problems associated with aging, wear and deterioration of components [13].

The probability density function $f(x)$ for the Weibull distribution is: 


$$
f(x)=\beta \eta^{-\beta} x^{\beta-1} \exp \left[-\left(\frac{x}{\eta}\right)^{\beta}\right]
$$

In the Weibull $p d f, \eta$ is the scale parameter and $\beta$ is called the shape parameter. $\beta$ parameter is related to the frequency of failure for observed components and $\eta$ is the time (for this study the number of pulses $N_{B D}$ ) at which $63.2 \%$ of components have failed.

The usual way to determine the Weibull parameters $\eta$ and $\beta$ is to analyze the cumulative Weibull distribution $F\left(N_{B D}\right)$ using a Weibull distribution plot. Indeed, $F\left(N_{B D}\right)$ is given by

$$
F\left(N_{B D}\right)=1-\exp \left[-\left(\frac{N_{B D}}{\eta}\right)^{\beta}\right]
$$

This function can be then linearized as follow:

$$
\ln \left[-\ln \left(1-F\left(N_{B D}\right)\right)\right]=\beta \ln \left(N_{B D}\right)-\beta \ln (\eta)
$$

The draw of $\ln \left[-\ln \left(1-F\left(N_{B D}\right)\right)\right]$ as a function of $\ln (\eta)$ should have a slope $\beta$ and intercept $\beta \ln (\eta)$ as shown in Figure 8.

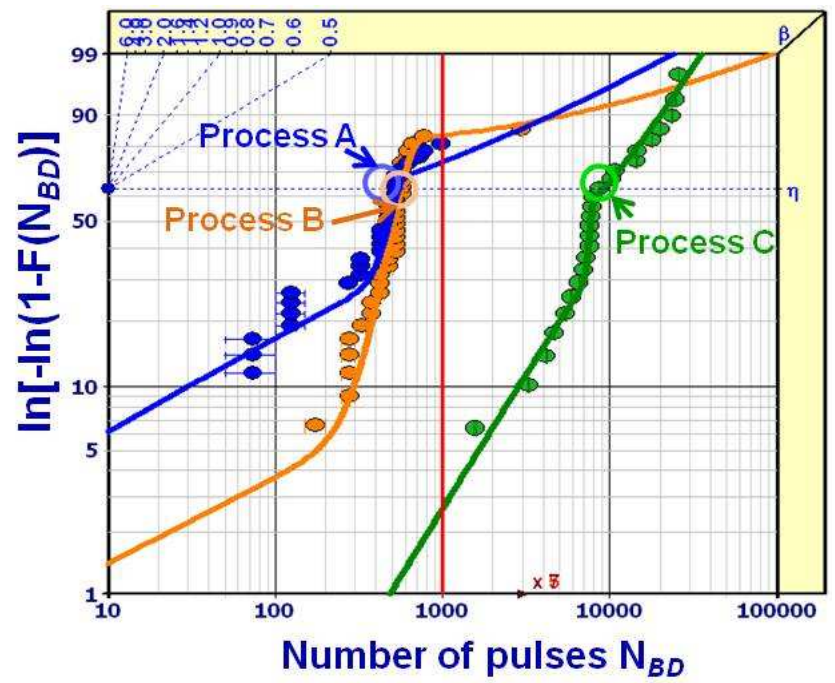

Figure 8: Plot of the cumulative Weibull distribution as a function of $N_{B D}$ for process A, B and C. $\eta$ parameter (circles) corresponds to the number of pulses after which $63.2 \%$ of components have failed while $\beta$ represents the slope of the distribution line.

To model the distribution accurately, two populations are required for process splits $\mathrm{A}, \mathrm{B}$ and $\mathrm{C}$. The flexibility and power of the Weibull-based analysis allow distinguishing two or several populations in a unique sampling where each considered population corresponds to a given failure mode characterized by the $\beta$ parameter.

The two $\beta$ and $\eta$ parameters sets calculated for all process splits are summarized in Table 6. $P_{1}$ and $P_{2}$ are the percentage of devices degraded according to a given failure mode (i.e. the two $\left(\beta_{1}, \eta_{1}\right)$ and $\left(\beta_{2}, \eta_{2}\right)$ Weibull distribution respectively).
Table 6: Experimental parameters $\eta$ and $\beta$ established from Weibull distribution for process $\mathrm{A}, \mathrm{B}$ and $\mathrm{C}$ splits using two populations. $\mathrm{P}_{1}$ and $\mathrm{P}_{2}$ correspond to the percentage of devices in each population.

\begin{tabular}{|c|c|c|c|}
\cline { 2 - 4 } \multicolumn{1}{c|}{} & Process A & Process B & Process C \\
\hline $\boldsymbol{N}_{\boldsymbol{B} \boldsymbol{D}}=\boldsymbol{\eta}_{\boldsymbol{1}}$ & $\mathbf{1 2 1 9}$ & $\mathbf{6 4 4 7}$ & $\mathbf{1 2 0 4 4}$ \\
\hline$\beta_{1}$ & 0.47 & 0.53 & 1.38 \\
\hline $\mathrm{P}_{1}$ & $44 \%$ & $24 \%$ & $74 \%$ \\
\hline $\boldsymbol{N}_{\boldsymbol{B} \boldsymbol{D}}=\boldsymbol{\eta}_{2}$ & $\mathbf{4 6 7}$ & $\mathbf{5 3 0}$ & $\mathbf{7 6 9 2}$ \\
\hline$\beta_{2}$ & 4.10 & 4.50 & 31.9 \\
\hline $\mathrm{P}_{2}$ & $56 \%$ & $76 \%$ & $26 \%$ \\
\hline
\end{tabular}

One of the main advantages of the Weibull analysis is that it gives clues on the underlying physical-failure mechanisms. Indeed, The observed $\beta>1$ correspond to wear out or intrinsic failures whereas $\beta<1$ reveal infant mortality or defective items failing early, namely failure related to extrinsic mechanism [14].

Notice that the population with an infant mortality $(\beta<1)$ is reduced from process A to process B ( $44 \%$ down to $24 \%$ ) going with an enhanced $\eta$ (1219 up to 6447). This behavior benefits to the second population obtaining a $\beta_{2}>1$, according to the evolution of the parameter $\eta$. Indeed, $\eta$ is improved for process B compared to process A. Furthermore, the information provided by the Weibull statistical analysis on physical failure is more meaningful than that given by both normal and lognormal distributions.

We evidenced that the widespread results related to early failures were due to initial defects in the metallization process which have been identified from failure analysis. For the process $\mathrm{C}$, infant mortality is solved and no defect of metallization is observed in the devices. Also, it should be noticed that this initial defect is the origin of failure through an electro thermo migration phenomenon [3].

The Weibull distribution analysis reveals that process $\mathrm{C}$ is more reliable than process splits A or B. Indeed, the $\eta$ parameters are much higher for both considered populations than for process $\mathrm{A}$ and $\mathrm{B}$. The minimum number of pulses leading to degradation exceeds the 1,000 ESD pulses demanded in the specifications. We are still investigating the correlation of the physical failure analysis with statistical distributions following two populations for process $\mathrm{C}$.

A cumulative probability graph are a common way of showing reliability data. Histogram plots is another representation that might be more understandable to non-expert of lifetime studies. Hereafter, we present the fit of discrete distribution results with the three statistic distributions used in this study. Figure 9,10 and 11 show the quality of the fit for the Weibull representation compared with normal and lognormal distributions. Moreover, the two populations can be quite easily distinguish. 


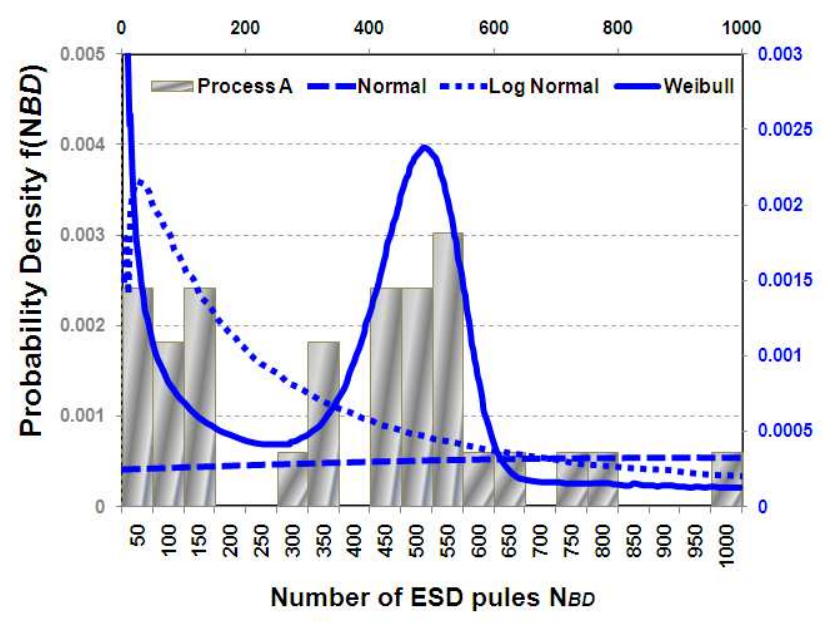

Figure 9: Probability density function following normal, lognormal and Weibull distributions and discrete distributions with a step of 50 pulses for Process A.

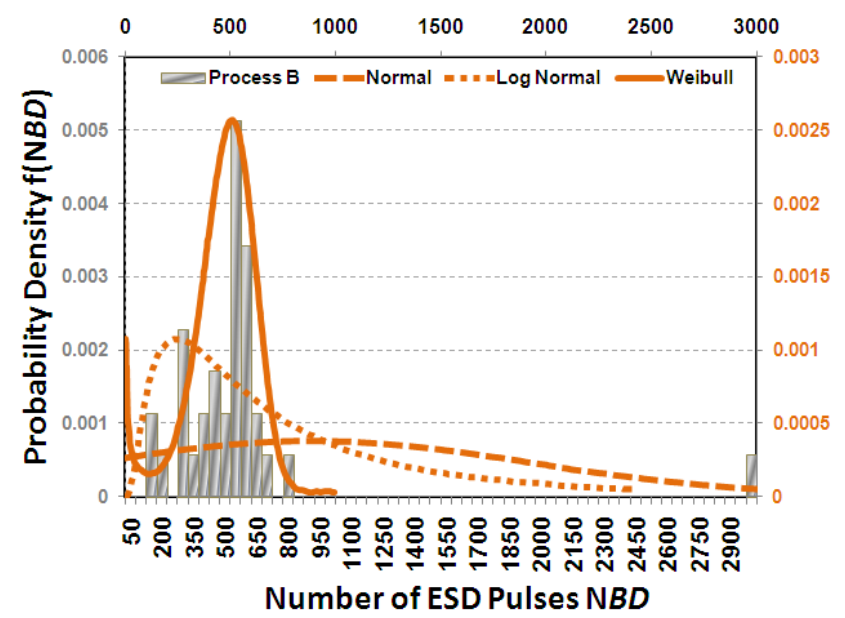

Figure 10: Probability density function following normal, lognormal and Weibull distributions and discrete distributions with a step of 50 pulses for Process B.



Figure 11: Probability density function following normal, lognormal and Weibull distributions and discrete distributions with a step of 1000 pulses for Process C.
Finally, the Weibull parameters afford a physical interpretation and enable the characterization of quite scattered results using an accurate fit with multiple populations. Indeed, Weibull analysis of the experimental results enables comprehensive and quantitative interpretation. This gives strong bases to define the concept of "ESD endurance" that we would like to propose as one of the outcome of this work; ESD endurance being the capability of a device to sustain repetitive pulse, in contrast to ESD robustness that is the highest stress level the device can survive.

It is important to notice that one cannot define a unique and ideal endurance requirement to qualify a product. Indeed endurance requirement will strongly depends on the application and its mission.

The method proposed here allows an effective way to compare different solution regarding reliability, which is not the case with classical ESD robustness. As a rule of thumb, we still can define a more desirable configuration of the results that is having a unique population $(\mathrm{P} 1=100 \%, \mathrm{P} 2=0)$ with a $\beta>1$.

\section{CONCLUSION}

While standard "single" ESD robustness is shown to be equivalent on three process splits it appears to be dramatically different regarding repetitive ESD stress, proving that the concept of ESD endurance is a key aspect to evaluate effectively system level robustness.

A meaningful statistical method has been carefully investigated to provide a good estimation of the HMM reliability in a repetitive ESD stress mode for system level protection diodes. We demonstrate that using a good statistical representation of results is crucial to qualify products robustness and also as a way of improving their reliability.

The Weibull analysis is shown to be relevant for ESD endurance investigations. It allows defining, studying, analyzing and comparing ESD endurance of given devices in a formal and powerful way. In addition, ESD specifications could be established by this mean to guarantee reliability towards repetitive HMM stresses.

For the reasons detailed in the introduction, we believe the ESD endurance analysis approach could drastically improve ESD robustness and reliability at system level in end-user applications when compared to the blind and often costly approach of requiring higher and higher protection level. We believe this approach might also be systematically used during protection device development in order to avoid specific failure mechanisms related to repeated ESD stresses and at least be used to improve in a controlled and measurable way their ESD endurance. Furthermore, while classic system ESDrobustness design still requires understanding and dedicated studies, an additional step forward would be to take into account ESD endurance upfront as a design target. Lots of efforts would be necessary in these regards but it could result in major system reliability improvements.

\section{REFERENCES}

[1] R.G. Renninger, "Optimized Statistical Method for System-level ESD Tests", International Symposium on Electromagnetic compatibility, pp. 474-484, 1992. 
[2] ESD Association Standard ESD DSP5.6.2009. Human Metal Model (HMM) - component level of ESD Association WG 5.6, 2009.

[3] M.Diatta, D.trémouilles, E.Bouyssou, R. Perdreau, C. Anceau, M. Bafleur, "Understanding the Failure Mechanisms of Protection Diodes During System Level ESD: Toward Repetitive Stresses Robustness", IEEE Transactions On Electron Devices, Vol. 59, N .1 , January 2012.

[4] I. Laasch, H. M. Rittern, A. Werner, "Latent damage due to multiple ESD discharges" EOS-ESD Symposium Proceedings, 2009, pp. 1-6.

[5] M. Diatta, E. Bouyssou, D. Trémouilles, P. Martinez, F. Roqueta, O. Ory, M. Bafleur, "Failure mechanisms of discrete protection device subjected to repetitive electrostatic discharges (ESD)", Microelectronics Reliability 49, 2009, pp. 1103-1106.

[6] Keppens, Bart; De Heyn, Vincent; Mahadeva Iyer, Natarajan; Groeseneken, Guido; "Contributions to standardization of transmission line pulse testing methodology", in proceedings of the 2001 EOS/ESD Symposium, Portland Oregon, US, September 11-13, 2001.

[7] R. G. Renninger," Improved Statistical Method for System-Level ESD Tests", International Symposium on Electromagnetic Compatibility, pp. 20-25, 1993.

[8] Life Data Analysis Reference, ReliaSoft Publishing, 1996.

[9] L. Hribrar, "Software Component Quality Prediction in the Legacy Product Development Environment Using Weibull and Other Mathematical Distributions, 17 th International Conference on Software, Telecommunications \& Computer Networks, 2009, pp254-259.

[10] C. F. M. Carobbi, M. Cati, L. M. Millanta, "Using the Log-Normal Distribution in the statistical treatment of experimental Data affected by Large Distribution", International Symposium on Electromagnetic Compatibility, pp. 818-816, 2003.

[11] S. Vittal, R. Phillips, "Uncertainty Analysis of Weibull Estimators for Interval-Censored data", Annual Reliability and Maintainability (RAM'S) Symposium, pp. 292-297, 2007.

[12] W. Weibull, "A statistical distribution function of wide applicability”, J. Appl. Mech. 18:293-7, 1951.W. Weibull, 1951.

[13] R. Billinton and R.N. Adam, "Reliability Evaluation of Engineering Systems: Concepts and techniques", Books, Boston, 1983.

[14] R. B. Abernethy, "The new Weibull handbook", $4^{\text {th }}$ Edition, 2003.

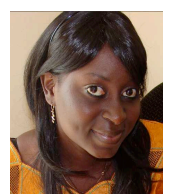

Marianne Diatta was born in January 1985 in Dakar, Senegal. She received the M.Sc Degree in Micro and Nanotechnologies engineering in 2008 from Université Paris Sud XI, Orsay in France. In January 2012, she received her $\mathrm{Ph} . \mathrm{D}$ in microelectronics from the Laboratoire d'Analyse et d'Architechture des Systèmes of Centre National de la Recherche Scientifique (LAAS-CNRS) in Toulouse, FRANCE. During her Ph.D degree, her research activity focused on the reliability of ESD protection devices in a closed collaboration with the R\&D of STMicroelectronics in Tours, France. Statistical tools, failure analysis, electrical and ESD characterizations constitute the means exploited to define the failure mechanism in the goal to improve robustness and reliability.

This work was carried out closely with the.

Since April 2012, Dr. Diatta joined the R\&D department of STMicroelectronics in Tours, France. Integrated in the Wafer Level Reliability and Device Characterization Team, her investigations are focused both on ESD Protection quality and Dielectrics reliability for metal-insulatormetal applications.

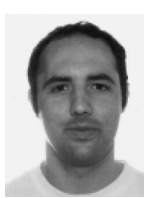

David Trémouilles (M'10) received the M.S. degree in electrical engineering and his Ph.D. degree in microelectronic circuit and microsystem design from the Institut National des Sciences Appliquées, Toulouse, France, in 2000 and 2004 , respectively. During his $\mathrm{Ph} . \mathrm{D}$. degree his research activity focuses on the design optimization, simulation, and modeling of ESD protections for bipolar CMOS technologies. This work was carried out at the Laboratoire d'Analyse et d'Architecture des Systèmes of Centre National de la Recherche Scientifique (LAAS/CNRS) in collaboration with On Semiconductor Toulouse. In October 2004, he was with the reliability researcher group, Interuniversity. Microelectronics Center, Leuven, Belgium, where he was granted a Marie Curie Intra-European fellowship from the European Community. In April 2007, he was with LAAS to study alternative materials and strategies to protect integrated circuits and systems against ESD and electromagnetic interference in the framework of a Marie Curie European Reintegration Grant. In 2008, he succeeds in the CNRS researcher entrance competition, and he has been a Full-Time CNRS Researcher since October 2008. His research interests were on the impact of new technology options and device architecture on ESD robustness, and innovative ESD protection for radio-frequency circuits. Dr. Trémouilles served as a member of the Technical Program Committee of the EOS/ESD Symposium 2007 and 2008, and as chairman of the "ESD Device testing" and "System level ESD" sessions at the 2009 symposium.

Emilien Bouyssou was born in 1978, he received the M.S. degree from the Graduate School of Physics and Chemistry of Bordeaux (ENSCPB) in 2002 and the Ph.D. degree in electronics from the University of Tours, Tours, France, in 2006. His Ph.D. work was performed in collaboration with STMicroelectronics,Tours, and concerned the electrical characterization and the reliability performance of high-density PZT capacitors technology elaborated by sol-gel processing. He is currently with STMicroelectronics, leading the Wafer Level Reliability and Device Characterization team in the Research and Development Department. His main research areas concern high- $k$ materials, dielectric breakdown in metal-insulator-metal capacitors structures, ESD failure mechanisms, and new energy sources.

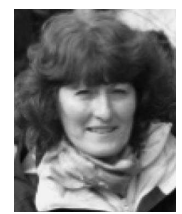

Marise Bafleur was born in June 1956 in Gimont, France. She received the Engineer degree in solidstate physics from the Institut National des Sciences Appliquées of Toulouse, Toulouse, France, in 1979 and the Ph.D. and State Doctorate degrees from Paul Sabatier University, Toulouse, in 1982 and 1987 , respectively.

From 1979 to 1982, she was working on the defect characterization of molecular-beam-epitaxygrown GaAs layers. In 1983, she was with the Centre National de la Recherche Scientifique (CNRS) at the Laboratoire d'Analyse et d'Architecture des Systèmes (LAAS), Toulouse. From 1983 to 1987, after one year with IBM-COMPEC, Bordeaux, France, working on the characterization of very-large-scale-integration ICs via reverse engineering techniques. She devoted her research activities to CMOS digital IC design and modeling of their dynamic behavior. From 1987 to 1994, she oriented her activity toward smart power IC design and technology. From 1991 to 1994, she was a Project Leader with the Prometheus/Prochip European Program devoted to the introduction of smart power in the automotive environment in cooperation with Renault and Peugeot automotive manufacturers. She then spent three years with Motorola in Phoenix, AZ, first as a Low-Power Designer and then working on TCAD predictive engineering. Since the end of 1997, she has been with the LAAS Research Institute, leading a research activity. 